\title{
Removal of Organic material contaminants from wastewater of a petroleum refinery by Employing Ultrasound
}

\author{
Najwa S. Majeed ${ }^{*}$ and Samira Najem Abdullah \\ Chemical Engineering Department/College of Engineering/University of Baghdad \\ Received 01 Jan 2018, Accepted 04 March 2018, Available online 07 March 2018, Vol.8, No.2 (March/April 2018)
}

\begin{abstract}
In this study, the reduction of organic pollutants from wastewater was investigated. Ultrasonic radiation was approved as the usage method. Effective parameters such as the period of ultrasonic radiation (10-35min), ultrasonic power (40-200watt) and initial organic material concentration (123-150 $\mathrm{mg} / \mathrm{l}$ ) were tested to determine their effects on organic material removal percentage and turbidity regress. It has been found that a time interval of 30 minutes of continuous exposition of dissolved organic material to the field of ultrasound come to $76 \%$ removal at initial organic material concentration of $123 \mathrm{mg} / \mathrm{l}$. Significant temperature change occurred which was about $\left(20-33^{\circ} \mathrm{C}\right)$ rise in 35 minutes. However, this temperature change had no significant influence on efficiency of the treatment. Also it was found that the turbidity deceases with time from 98 to 34 at 35 min of exposure to Ultrasonic irradiation.
\end{abstract}

Keywords: Ultrasonic ,organic pollutantas, wastewater treatment, advanced oxidation process

\section{Introduction}

The reuse of wastewater is increasingly confirmed as a method for protect reduced freshwater sources and as a means of preserving the aqueous environment due to pollutants in wastewater. Although secondary and tertiary treated wastewater is often throw away into the river, it cannot be recycled without more treatment. One of the factors that concern human and environmental health is the composition of organic matter. Organic contamination is the expression used when huge amounts of organic compounds. They originate from local sewage, urban, industrial wastes, sludge and refineries. This waste organic matter should be carefully described so as to find the best treatment method for water recycle (Ali et al, 2012).

Different methods of treatment can be used to reduce organic materials. These processes involve flocculation, adsorption, biofiltration, ion exchange, advanced oxidation process, and technology of membrane. The elimination efficiency is examined in terms of total organic carbon removal, endocrinehydrophobic and hydrophilic, the molecular weight distribution of organic material wide varieties of mercantile chemicals are applied organic compounds, resulting in producing of various types of wastewater with large amounts of organic waste composition.In recent years, advanced oxidation processes (AOPs) have arisen as hopeful new technologies for the

*Corresponding author's ORCID ID: 0000-0003-0994-4027, DOI: https://doi.org/10.14741/ijcet/v.8.2.9 dissolution of organic pollutants. These processes consist of photochemical degradation, radiolysis, and sono-chemical degradation. Ultrasonic irradiation is the technology that has been widely used as an advanced oxidation process (AOP) for treatment of wastewater (N. Mahamuni et al, 2010).

AOPs are described as the processes that produce hydroxyl radicals in necessary amounts to be capable to oxidize most of the complex chemicals found in the discharge water (P.R. Gogate et al, 2004).Cavitations is one of the main oxidation processes, defined as the phenomenon in which a large amount of energy is released in less than a microsecond by micro bubbles and small cavities that form, enlarge and implode (K. Suslick, 1989).

In the case of acoustic cavitation, the occurrence of alternate compression and rarefaction cycles is due to sound waves with high frequency (as ultrasound) in the range of $16 \mathrm{KHz}-100 \mathrm{MHz}[3,5]$. This leads to sonochemical pyrolytic reactions recognized by high temperature and pressure within the cavitations bubbles formed by ultrasonic irradiation (W.Songlin et $a l, 2008$ ). Thus, free radicals such as $\mathrm{H}, \mathrm{OH}$, and $\mathrm{H} 2 \mathrm{O}$ are created in a very short (millisecond) time in solution. These roots are included in the fast oxidation of inorganic and organic substances and degradation of complex composition in solution (E.Ozturk et al, 2015). The capacity to remove toxic elements from wastewater by ultrasonic technique depends on different process parameters (N.Matei, 2014) such as pollutant initial concentration, intensity and frequency of irradiation, treatment time, temperature, $\mathrm{pH}$, and 
sample volume and treatment type (continuous or intermittent). Also, cavitational medium (whether in a stable vibration the bubble keep on or it is changed into a transient collapse), occurs according to additional parameters such as original size of the bubble, surface tension and viscosity (J.Huang et al, 1995).

US is longitudinal wave with frequency above 20 $\mathrm{KHz}$ and this frequency is above the acoustic range (20 $\mathrm{Hz}$ to $20 \mathrm{KHz}$ ) that humans can hear and under the mega-acoustic zone $(>600 \mathrm{KHz})$ (Deymier et al., 2004(10) , Wong, 2002)(11).In US waves, energy is transmitted by vibration of the molecules in the environment where the wave is propagated (Bello et al., 2005)(12).

The aim of this study was to investigate the effects of ultrasonic irradiation as a new clean technology for the removal of Organic Material contaminants from wastewater of a petroleum refinery, the effects of increasing ultrasound times (10-35 min) , ultrasound power $((40-200 W))$ and Organic Material initial concentration $(123 \mathrm{mg} / \mathrm{l}, 150 \mathrm{mg} / \mathrm{l})$ on the removal percentage was studied.

\section{Experimental}

\section{Materials}

Wastewater was collected from the effluent outlet from AL-Daura petroleum refinery.

\section{Ultrasound Device}

An ultrasound device equipped with a sonotrode horn (horn tip with $5 \mathrm{~mm}$ diameter) was turned at $24 \mathrm{KHz}$ (Figure

1).

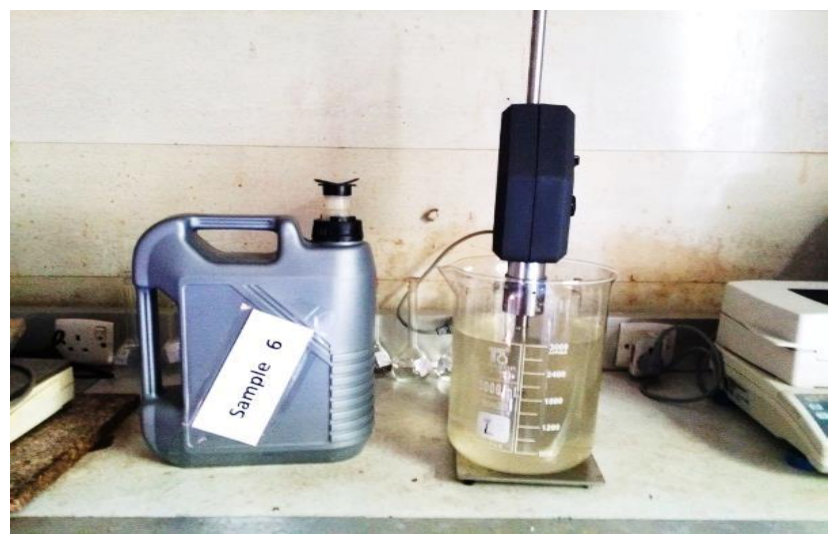

Figure 1 Ultrasound device

The US radiation source has been equiped to the laboratory building reactor. The applied US power was adaptable from 40 to 200W.The reactor was exposed to the air. The probe was injected into the middle of the $3000 \mathrm{~mL}$ reactor with an inner diameter of $8.5 \mathrm{~cm}$ and $8.8 \mathrm{~cm}$ heights. The wastewater capacity in the reactor was $2000 \mathrm{~mL}$ that horn was injected in $25 \mathrm{~cm}$ from bottom of reactor. At laboratory temperature the setup was operated.This part of experimental work was performed at different power densities (40-200 watt). The sonochemical degradation of the organic materials was evaluated using 2 different initial concentrations 123 and $150 \mathrm{mg} / \mathrm{L}$ with aduration of ultrasonic irradiation from (10min to $35 \mathrm{~min})$.

Table 1: Characteristics of ultrasound apparatus

\begin{tabular}{c|c}
\hline \multicolumn{2}{c}{ Technical Data } \\
\hline Dimensions & UP200S \\
Operating Frequency & $24 \times W \times H) 257 \times 157 \times 130 \mathrm{~mm}$ \\
Pulse range & $0-100 \%$ \\
Power & $200 \mathrm{~W}$ \\
Power control & Amplitude $20-100 \%$ \\
Power supply & $230 \mathrm{~V}, 2 \mathrm{~A}, 50-60 \mathrm{~Hz} 110-120 \mathrm{~V}, 4 \mathrm{~A}$, \\
Weight & $1,5 \mathrm{Kg}$ \\
Capacity Sonotrode & $0.1-3000 \mathrm{~mL}$ \\
\hline
\end{tabular}

\section{Results and Discussion}

\subsection{Effect of Ultrasound Power}

In this study, experiments were conducted with difference in the US radiation strength. The time interval was applied using $30 \mathrm{~min}$ of power range (40200W). Figure (2) shows the effect of the power density on the sonolysis process.

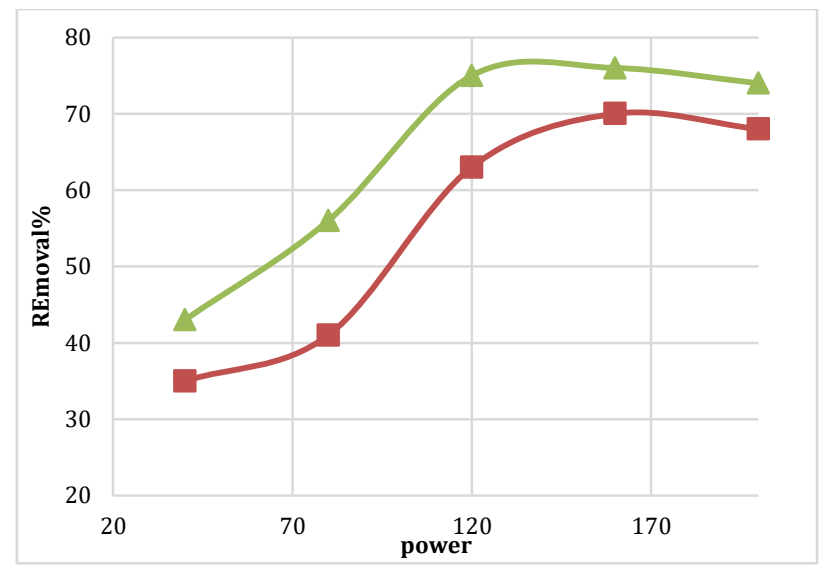

Figure 2 Percent of Removal at various US powers (Concentration of initial DOM $123 \mathrm{mg} / \mathrm{L}$ and 150 $\mathrm{mg} / \mathrm{L})$, Time $20 \mathrm{~min}, \mathrm{PH}=7.8$

It can be observed that greater power density led to deterioration of dissolved organic material faster because of increased cavity rate in the unit volume of solution of the highest degrees of total pressures pulses (pressure pulse due to the collapse of single cavity $\times$ number of cavities) and more active root production. In sonolysis of aqueous solutions the thermal dissociation of water to hydrogen atom and hydroxyl roots. Increased US intensity has been shown to increase the rate of degradation of organic compounds. Moreover, the pulse and bubble collapse in the reaction cell occurred more rapidly, increasing the number of cavitation bubbles and concentrated $\mathrm{OH}$ radicals by increasing the strength of the US. These 
radicals reacted $\mathrm{OH}$ with $\mathrm{DOM}$ in the solution. In a higher power of irradiation, a great number of cavities or gas bubbles in the solution were made and the sound waves were dispersed to the walls of the container or back to the transducer. Then, a smaller level of energy fixing or strength occurred although the container was subjected to greater and greater concentrations.

Figure (2) shows that the most efficient power was 160 watt with $70 \%$ and $76 \%$ removal efficacy for intial concentration of $123 \mathrm{mg} / \mathrm{l}, 150 \mathrm{mg} / \mathrm{l}$ respectively.The same conclusion was obtained by (Sponza and Oztekin 2013) (13).

\subsection{Ultrasound Time Effect}

Tests were accomplished with 10 to $35 \mathrm{~min}$ of radiation time and the collected samples were examined. The difference of percentage degeneracy in DOM removal was shown in figure(3) with time at 120 $\mathrm{W}$ power and initial concentrations of oil (123-150) $\mathrm{mg} / \mathrm{L}$. With process time oil degeneracy has been increased and the higher values of degeneracy occurs in $30 \mathrm{~min}$. Because after $30 \mathrm{~min}$ a great variation did not happen, this time was chosen as the perfect time. Comparable results are seen in the workof Katsumata et al. (2007) (14). Where in $30 \mathrm{~min}$ of US, the dissolved gases occurrence in the medium increased and enhance the extent of cavitation due to possible intents. Also, the cavitations may be occur due to the severity of the cavitations in result of a high total pulse pressure volume. Gogate et al. (2003) (15) found similar effects with tests on decay of aqueous fluvic acid solutions in the US setup.

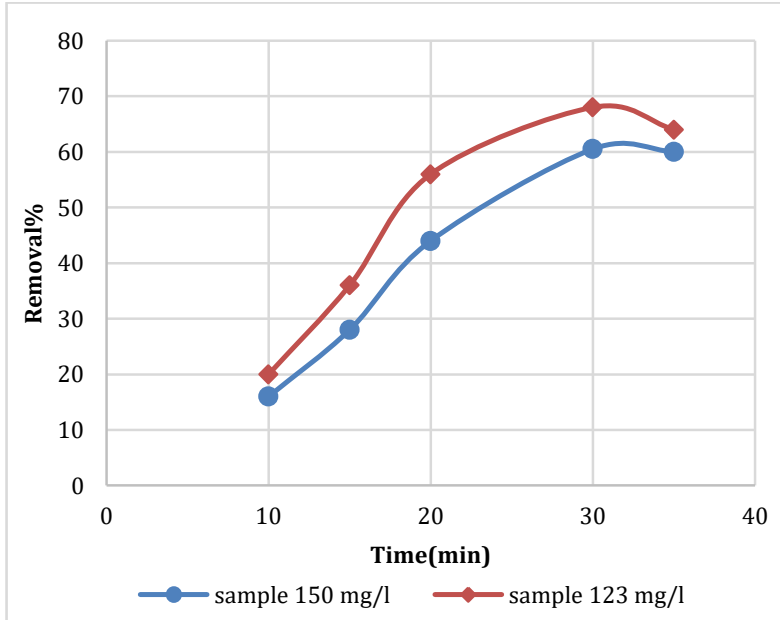

Figure 3 Percent Removal at various US powers (DOM initial concentration $123 \mathrm{mg} / \mathrm{L}$ and $150 \mathrm{mg} / \mathrm{L}$ ), Time 20 min, $\mathrm{PH}=7.8$ and Amplitude 60\%

\subsection{Initial concentration of DOM Effect}

Figure (3) shows the influence of initial concentration of DOM (123-150 mg/L) with DOM disgrace in $30 \mathrm{~min}$ and $120 \mathrm{~W}$ ultrasound. Apparently, the disgrace was reducing in DOM maximum concentration. The effects showed an increasing decay with time but at high concentration the decay was lower. These outcomes showed that the rate of disgrace was in reverse relative to the DOM concentration initially taken.

The current research notes are in good agreement with the earlier results found by Maleki et al. (2007) (16) and Kobayashi et al. (2014)(17).

Effect of Ultrasound on the properties of the remaining solution

\section{Ultrasound effect on temperature}

The temperature rises with sonication in an ultrasonic reactor, if not controlled. The temperature increase in $35 \mathrm{~min}$ was about $20-33^{\circ} \mathrm{C}$, and due to the cavitation. The temperature increase at $24 \mathrm{KHz}$ frequency was about $2-5{ }^{\circ} \mathrm{C}$ more than at the frequency of $130 \mathrm{KHz}$ but this difference was not significant $(\mathrm{p}>0.05)$.

\section{Effect of Ultrasound on Turbidity}

Turbidity is the main physical distinguishing property of water. It is affected by hanging or dissolved substances such as soil, sludge, poorly divided inorganic and organic material, dissolvable organic complexes, (plankton and other microscopical organisms).Figure(4) shows the variation of the turbidity over time, it was clear that the turbidity deceases with time.

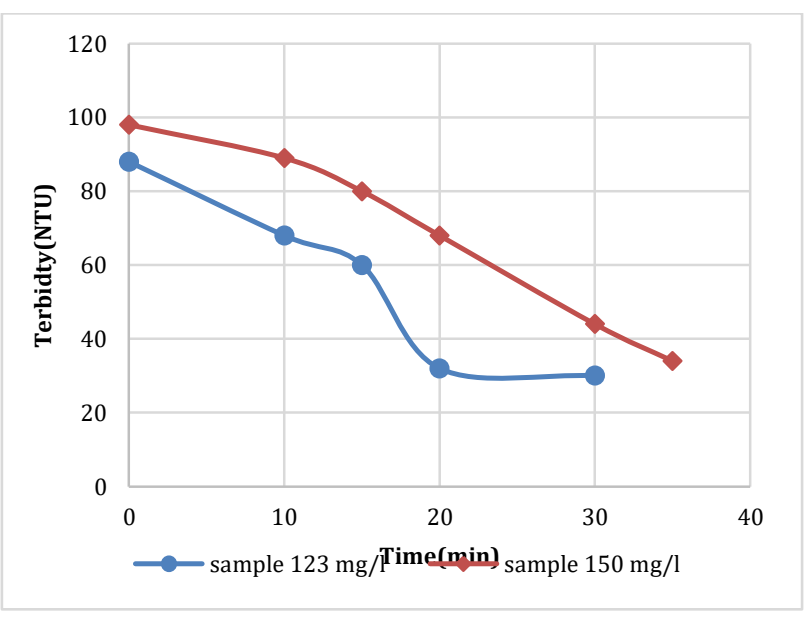

Figure 4 Effect US on Turbidity at different times (DOM at initial concentration $123 \mathrm{mg} / \mathrm{L} \& 150 \mathrm{mg} / \mathrm{L}$ ) , Frequency $24 \mathrm{KHz}$, power 200 watt and $\mathrm{PH}=7.8$

\section{Conclusions}

It seems that the sonochemical degradation technique bodes well for many organic compounds, controlled by pyrolysis and/or free radical reactions. The degree of degradation depends on both acoustic parameters (time, power, initial concentration of DOM).When power is larger, transmission of ultrasonic energy into the container also become larger leading to a higher 
cavitations activity caused by a higher concentration of $\mathrm{OH}$ radicals. In the lower frequency, more violent cavitations will be formed, causing in higher temperatures and pressure. The most effective power was found to be 160 watt with $70 \%$ and $76 \%$ removal efficiency for intial concentration of $123 \mathrm{mg} / \mathrm{l}, 150$ $\mathrm{mg} / \mathrm{l}$ respectively. The removal rate was also increased with the increase in exposure time and the highest removal rate was 30 times. The results showed that the percentage removal decreases the concentration of dissolved organic substances in the initial increases.

Significant temperature change happened which was about $\left(20-33^{\circ} \mathrm{C}\right)$ increase in 35 minutes. The turbidity was deceased from 98 to 34 at initial organic material concentration of $150 \mathrm{mg} / \mathrm{l}$.

\section{References}

Ali, I., Mohd. Asim, Tabrez A. Khan, 2012, Low cost adsorbents for the removal of organicpollutants from wastewater. Journal of Environmental Management; 113, 170-183.

N. Mahamuni et al., Advanced oxidation processes (AOPs) involving ultrasound for wastewater treatment: A review with emphasis on cost estimation, ultrasonic sonochemistry 17 (2010), 990-1003.

P.R. Gogate et al., (2004), A review of imperative technologies for wastewater treatment I: oxidation technologies at ambient conditions, Advances in Environmental Research 8,501-551.

K. Suslick, (1989), The chemical Effects of ultrasound, Scientific American 80-86.

K.Suslick,(1999), Acoustic cavitations and its chemical consequences, phil. Trans. Roy. Soc.

W.Songlin et al., (2008), Removal of organic material and ammonia nitrogen from landfill leachate by ultrasound, Ultrasonics Sonochemistry 15 933-937.
E.Ozturk et al. (2015), Evaluation of ammonia-nitrogen removal efficiency from aqueous solutions by ultrasonic irradiation in short sonication periods, Ultasonics Sonochemistry 26 422-427.

N.Matei, (2014), Ultrasonic effect in ammonia-water treatment. A review, The 9th Symp Recycling technol. And sustainable develop. Serbia.

J.Huang et al., (1995), Low-MHz frequency effect on a sonochemical reaction determined by an electrical method, Ultras. Sonoch. 2, 93-97.

Deymier PA, Vasseur J0, Khelif A. 2004,Second-order sound field during megasonic cleaning of patterned silicon wafers: Application to ridges and trenchesJournal of Applied Physics 90, 4211-4218. 2004.

Wong KYK. 2002, Ultrasound as A Sole or Synergistic Disinfectant in Drinking Water. Master Thesis. Worcester Polytechnic Institute, USA.

Bello ARC, Angelis DF, Domingos RN. 2005, Ultasound Efficiency in Relation to sodium Hypochlorite and Filtration Adsorption in Microbial Elimination in a Water Treatment Plant, Brazilian Archives of Biology and Technology, 48: 739-745.

Delia Teresa Sponza and Rukiye Oztekin, 2013, Treatment of the live Mill Industry Wastewater with Ultrasound and Some Nano-Sized Metal Oxides, Chemical Engineering \& Process Technology, Volume 4, Issue 2

Katsumata, H.; Kaneco, S.; Suzuki, T.; Ohta, K. \&Yobiko, Y. 2007. Sonochemical degradation of $2,3,7$, 8tetrachlorodibenzo-p-dioxins in aqueoussolution with Fe(III)/UV system. Chemosphere, 69:1261-1266.

Gogate PR, Wilhelm AM, Pandit AB. 2003. Some aspects of the design of sonochemical reactors. Ultrason. Sonochem, 10 325-330.

Maleki, A., Mahvi, A. H., Mesdaghinia, A. and Naddafi, K 2007,Degradation and toxicity reduction of phenol by ultrasound waves, Chem. Soc. of Ethiopia, 21, 33-38.

Kobayashi, D., Honma, C., Matsumoto, H., Takahashi, T. Kuroda, C.,Otake, K. and Shono, A. 2014. Kinetics analysis for development of a rate constant estimation model for ultrasonic degradation reaction of methylene blue,Ultrason. Sonochem, 21, 1489-1495. 